\title{
Suspectable Risk Factors of Congenital Anomaly in Dr. Hasan Sadikin General Hospital, Bandung, Indonesia
}

\author{
Pradistya Syifa Yudiasari ${ }^{1}$, Akhmad Yogi Pramatirta ${ }^{2}$, Sharon Gondodiputro ${ }^{3}$ \\ ${ }^{1}$ Faculty of Medicine Universitas Padjadjaran, ${ }^{2}$ Department of Obstetric and Gynecology Faculty \\ of Medicine Universitas Padjadjaran/Dr. Hasan Sadikin General Hospital Bandung, ${ }^{1}$ Department \\ of Public Health Faculty of Medicine Universitas Padjadjaran/Dr. Hasan Sadikin General Hospital \\ Bandung
}

\begin{abstract}
Background: Congenital anomaly is a disease of structural or functional alteration since birth. The cause of congenital anomaly is genetic, environtment, and unknown. The cause of congenital anomaly is unknown, made congenital anomaly is difficult to detect. Therefore, the objective of this study was to identify the suspectable risk factors of congenital anomaly.

Methods: This was a descriptive study. About 78 samples were taken by purposive sampling from medical records of patients with congenital anomaly in pediatric surgery ambulatory unit at Dr. Hasan Sadikin General Hospital (RSHS), Bandung from September to November 2014. From the selected medical records, an interview was carried out to the parents' patient to identify some suspectable risk factors. The collected data were analyzed and presented in tables.

Results: From 78 medical records, hirschprung disease was the highest among all type of congenital anomaly (29\%). The characteristic of congenital anomaly was mothers in the age of 20 -35 years (65\%), fathers' age was more than 20 years old, family history of congenital anomaly was $1 \%$, there was no history of previous congenital anomaly in previous pregnancy, infection history was $3 \%$, history of medication was $11.5 \%$, mother's BMI was in normal term $(18.5-24.9)$ as much as $65 \%$, no history of radiation, there was no history of chronic alcohol. History of smoking/passive smoking was high (65\%).

Conclusions: Hirschprung disease is the highest rate disease in congenital anomaly and smoking is a highest suspectable risk factor contribute to congenital anomaly.
\end{abstract}

Keywords: Congenital anomaly, hirschprung, infection, smoking

\section{Introduction}

Congenital anomaly is a disease of structural or functional alteration since birth. Congenital anomaly can cause spontaneous abortion, disability, and death at birth. ${ }^{1}$ In 2007 the prevalence of congenital anomaly in Indonesia was $6 \%$ and congenital anomaly was the majority cause of the late neonatal death. ${ }^{2}$ There are three causes of congenital anomalies: genetic (20\%), environment $(10 \%)$, and unknown causes (70\%). The congenital anomaly detection is hard, thus, prevention is not easy to be done. This study was carried out to identify to identify the suspectable risk factors of congenital anomaly .

\section{Methods}

A descriptive study was carried out to 78 samples. The samples were taken using purposive sampling method, from patients' medical record continued with patients' parents interview in pediatric surgery ambulatory unit, Dr. Hasan Sadikin General Hospital (RSHS), Bandung, from September to November 2014.

Ethical clearance was given by the Education and Research Division of RSHS. An inclusion criterion in this study was pediatric patients in RSHS who were diagnosed with congenital anomaly. This study had 17 variables, which consisted of type of congenital anomaly, parents' age, parents' occupation, history of

Correspondence: Pradistya Syifa Yudiasari, Faculty of Medicine, Universitas Padjadjaran, Jalan Raya Bandung-Sumedang Km. 21, Jatinangor, Sumedang, Phone: +62 81221332215 Email: pradistyayudiasari@yahoo.com 
Table 1 Distribution of Congenital Anomalies

\begin{tabular}{|c|c|c|c|c|}
\hline Characteristics & System & $\begin{array}{c}\text { Congenital } \\
\text { Anomalies Type }\end{array}$ & $\begin{array}{c}\text { Frequency } \\
\mathrm{n}=78\end{array}$ & $\begin{array}{c}\text { Persentage } \\
(\%)\end{array}$ \\
\hline \multirow[t]{13}{*}{$\begin{array}{l}\text { Congenital Anomalies Type } \\
\text { Based on Body System }\end{array}$} & Digestive & Fistula & 3 & $4 \%$ \\
\hline & & $\begin{array}{c}\text { Anorectal } \\
\text { malformation }\end{array}$ & 22 & $28 \%$ \\
\hline & & Mislocated anus & 1 & $1 \%$ \\
\hline & & $\begin{array}{l}\text { Hirschprung } \\
\text { disease }\end{array}$ & 23 & $29 \%$ \\
\hline & Abdominal Wall & Gastroschizis & 1 & $1 \%$ \\
\hline & & Hernia & 6 & $8 \%$ \\
\hline & & Omphalocele & 2 & $3 \%$ \\
\hline & & Rectocele & 1 & $1 \%$ \\
\hline & Genital & Hipospadia & 12 & $15 \%$ \\
\hline & & Hydrocele & 1 & $1 \%$ \\
\hline & & Uretrocele & 1 & $1 \%$ \\
\hline & $\begin{array}{c}\text { Chromosomal } \\
\text { Anomalies }\end{array}$ & Down syndrome & 4 & $5 \%$ \\
\hline & & Turner syndrome & 1 & $1 \%$ \\
\hline
\end{tabular}

congenital anomaly in the family, history of congenital anomaly in previous pregnancies, history of infections, history of medication, mothers' Body Mass Index (BMI), history of exposure to radiation, history of mothers' disease, alcohol consumption, smoking, physical abnormalities in parents, congenital anomaly detection,. The collected data were analyzed using frequency tabulation and were presented with tables.

\section{Results}

In this study, the highest number of congenital anomalies found was Hirschprung Disease
(29\%), followed by Anorectal Malformation System (28\%).

In this study, the majority of mothers' age (63\% of all 78 samples) was in $20-35$ years old age group. This age range is women's productive time to start a family, especially in Indonesia. The percentage of women with high risk occupation was $1 \%$. The highest percentage of women's occupation in this study was housewife. Most women in Indonesia tend to dedicate their time for family than working, which usually is men's job as the head of the family.

All fathers' age in this study was above 20 years old. This age was also a productive

Table 2 Distribution of The Parents' Age and Occupation

\begin{tabular}{lccc}
\hline \multicolumn{1}{c}{ Characteristics } & Category & Frequency $\mathbf{n = 7 8}$ & Percentage(\%) \\
\hline Mothers' age & $\leq 20$ years old & 2 & $2 \%$ \\
& $20-35$ years old & 49 & $63 \%$ \\
& $>35$ years old & 27 & $35 \%$ \\
Mothers' occupation & Job with risk & 1 & $1 \%$ \\
Fathers' age & $\leq 20$ years old & 0 & $0 \%$ \\
& $>20$ years old & 78 & $100 \%$ \\
Fathers' occupation & Jobs with risk & 6 & $8 \%$ \\
\hline
\end{tabular}


Table 3 Preconception Screening

\begin{tabular}{lccc}
\hline \multicolumn{1}{c}{ Characteristics } & Category & Frequency $\mathbf{n = 7 8}$ & Percentage(\%) \\
\hline $\begin{array}{l}\text { History of congenital anomaly in } \\
\text { family }\end{array}$ & Yes & 1 & $1 \%$ \\
Mothers' BMI & $<18.5$ & 12 & $16 \%$ \\
& $18.5-24.9$ & 51 & $65 \%$ \\
& $25-29.9$ & 13 & $17 \%$ \\
& $\geq 30$ & 2 & $2 \%$ \\
\hline
\end{tabular}

age for men to start a family or to work. The majority of fathers' occupation were not a high risk one, with entrepreneur being the highest percentage in this study. Patients' fathers were mostly work as merchant or stall seller.

Preconception screenings showed that congenital anomaly found in patients were mostly the first case in the patients' family because the number of congenital anomaly history in the study subjects was low. The majority of mothers' BMI were normal. This showed that mothers' nutritional statuses were still controlled. There were no physical abnormalities in parents. In all patients there was no maternal history of disease, such as congenital anomaly in the previous pregnancy.

The histories of infectious disease found were chikungunya and toxoplasmosis. The history of medication found was herbal medicine consumption in pregnancy. There was no alcohol consumption in pregnancy. Sixty-five percent of the fathers were smoking during pregnancy. This number was quite high, thus, smoking might contribute to congenital anomaly.

\section{Discussion}

The highest number of congenital anomaly found in this study was Hirschprung disease, which was 29\% of all 78 patients, of digestive system. Whilst in other studies, the highest number of congenital anomaly found was central nervous system, spina bfida. ${ }^{3,9}$

Congenital anomaly risk was higher in women younger than 20 years old and older than 35 years old, while in other study, congenital anomaly was found more in women older than 35 years. ${ }^{3}$ This might be caused by low number of samples in this study, narrow study area, which was limited to one hospital only, and common productive age in subjects which ranged between 20 to 35 years old. Meanwhile, fathers in other studies had similar mean age. ${ }^{3}$ Parents' occupation did not show relationship with congenital anomaly because almost all of the respondents worked with no risk.

Preconception screening showed that there were not many patients with congenital anomaly in family or previous pregnancy. BMI variable in this study was mostly normal, this result was relevant with other researches. ${ }^{4}$ But, high BMI value might cause cardiovascular anomaly in neonatal. ${ }^{4}$ Maternal disease which might cause congenital anomaly was diabetes, which showed $6 \%$ value in other researches. ${ }^{1,3}$ This showed an insignificant relationship between diabetes and congenital anomaly.

There was no history of alcohol consumption in pregnancy in this study. This might be caused by low alcohol consumption in Indonesia.

In other studies, alcohol consumption might cause neonatal death in every age. ${ }^{1,5}$ Teratogenic medication might become a risk for congenital anomaly occurrence. But, it was also found several medications which might cause congenital anomaly in other studies such as NSAID. ${ }^{6}$ NSAID might cause cleft lip, spine anomaly, and others. ${ }^{6}$ Antiretroviral consumption might also cause congenital anomaly. ${ }^{7}$ However, there are several medications which might prevent congenital anomaly prevalence, for example, folic acid consumption in pre-conception time. ${ }^{8}$ This can decrease neural tube defect risk. ${ }^{1,9}$ Medications found in this study was NSAID and herbal medicine consumption.

Histories of infection found in this study were toxoplasma and chikungunya infection. There was no radiation exposure history found. The highest percentage of characteristics found in this study was smoking, which was $65 \%$. Mostly, the smokers were the fathers. ${ }^{1}$ Further USG examination was supposed to be done though low socioeconomic value in patients' parents needs to be considered. Other studies showed that antenatal care was not done in Indonesia while as we know, 
antenatal care is a tool which can be used to detect congenital anomalies. Previous studies showed that congenital anomaly happened more frequently in parents who did not do continuous antenatal care. ${ }^{9,10}$ Primary care doctor also has to be more alert in 37 to 42 weeks of gestational age, since neonatal death occurs more frequently in those age period. ${ }^{10}$ This evidence shows that antenatal care is important.

One of several limitations of this study is medical records in Dr. Hasan Sadikin General Hospital are not written completely. Another limitation is samples were not taken maximally because the information found in medical records was limited. Samples taken were also not sufficient, since this study was done on one location only, which was Dr. Hasan Sadikin General Hospital, Bandung

In conclusions, smoking is a characteristic found with a highest percentage $65 \%$ of all patients characteristic found in parents of patients with congenital anomaly. Thus, smoking can be considered as a high risk characteristic in this study. The highest percentage of congenital anomaly was Hirschprung disease (29\%).

Preconceptional examination must be done as initial screening method of congenital anomaly. Other things that can be done include family risk screening, genetic counseling, prenatal or postnatal maternal disease which might affect the child's condition, multivitamin consumption, like folic acid consumption. Primary care doctors have to have a good communication skill if they want to let the patients' parents know that they have a risk of having baby with congenital anomaly, especially for mothers, who usually have more difficulty in accepting the reality that their children are diagnosed with congenital anomaly. ${ }^{11}$ Mothers' food, medication, and health condition have to be checked in pregnancy. Those things might affect fetus' development directly, thus, controlling those things might decrease congenital anomaly incidence in the future.

Finally, several suggestions are proposed to improve future studies similar with this study. First, medical records' recording system needs to be done so that other causes and factors affecting congenital anomaly incidence can be acknowledged. Analytic case control study can also be done to see whether there is any relationship between risk factors which might affect the occurrence of congenital anomaly.

\section{References}

1. WHO. Birth defects. Geneva: Sixty-Third World Health Assembly; 2010. http:// www.searo.who.int/topics/birth_defects/ en/

2. Badan Penelitian dan Pengembangan Kesehatan Departemen Kesehatan Republik Indonesia Riset kesehatan dasar: Laporan Nasional 2007. .Jakarta: Badan Penelitian dan Pengembangan Kesehatan Departemen Kesehatan Republik Indonesia; 2008 3. Made Prabawa. Angka kejadian bayi lahir dengan kelainan kongenital [thesis]. Semarang: Universitas Diponegoro; 1998.

3. Best KE, Tennant PWG, Bell R, Rankin J. Impact of maternal body mass index on the antenatal detection of congenital anomalies. BJOG. 2012;119(12):1503-11.

4. O'Leary C, Jacoby P, D'Antoine H, Bartu A, Bower C. Heavy prenatal alcohol exposure and increased risk of stillbirth. BJOG. 2012;119(8):945-52.

5. Hernandez RK, Werler MM, Romitti P, Sun L, Anderka M. Nonsteroidal antiinflammatory drug use among women and the risk of birth defects. Am J Obstet Gynecol. 2012;206(3):228.e1-8.

6. Knapp KM, Brogly SB, Muenz DG, Spiegel HM, Conway DH, Scott GB, et al. Prevalence of congenital anomalies in infants with in utero exposure to antiretrovirals. Pediatr Infect Dis J. 2012;31(2):164-70.

7. Czeizel AE. The primary prevention of birth defects: Multivitamins or folic acid? Int J Med Sci. 2004;1(1):50-61.

8. Parmar A, Rathod SP, Patel SV, Patel SM. A study of congenital anomalies in newborn. Natl J Integr Res Med. 2010;1(1):13-7.

9. Rosenstein MG, Cheng YW, Snowden JM, Nicholson JM, Caughey AB. Risk of stillbirth and infant death stratified by gestational age. Obstet Gynecol. 2012;120(1):76-82.

10. Fonseca A, Nazaré B, Canavarro MC. Patterns of parental emotional reactions after a pre-or postnatal diagnosis of a congenital anomaly. J Reprod Infant Psychol. 2011;29(4):320-33. 